\title{
Downregulation of ROS1 enhances the therapeutic efficacy of arsenic trioxide in acute myeloid leukemia cell lines
}

\author{
JUN LI \\ Department of Hematology, The First Affiliated Hospital of Bengbu Medical College, Bengbu, Anhui 233004, P.R. China
}

Received May 29, 2016; Accepted August 1, 2017

DOI: $10.3892 / \mathrm{ol} .2018 .8458$

\begin{abstract}
The present study investigated the function of ROS proto-oncogene 1 receptor tyrosine kinase (ROS1) in regulating the migration and proliferation of acute myeloid leukemia (AML) cells through $\mathrm{Wnt} / \beta$-catenin signaling, and in arsenic trioxide (ATO) treatment. The migration and proliferation of multiple ROS1-silenced leukemic cell lines was assessed, and the expression levels of proteins associated with $\mathrm{Wnt} / \beta$-catenin signaling were determined using western blot analysis. Compared with the AML control cells, ROS1-knockdown cells exhibited increased migration and proliferation, and the significant downregulation of $\beta$-catenin expression. Additionally, ROS1 knockdown sensitized AML cells to the effects of chemotherapeutic ATO. The results of the present study demonstrated that, in leukemic cell lines, ROS1 counteracted the effects of ATO on migration and proliferation, suggesting that ROS1 may be a potential therapeutic target in patients with AML undergoing ATO treatment. The results of the present study provided novel insight into the function of ATO and ROS1 in regulating AML progression.
\end{abstract}

\section{Introduction}

Acute myeloid leukemia (AML) is a malignancy characterized by abnormal excessive proliferation of hematopoietic cells in the bone marrow (1). Cytotoxic chemotherapy and bone marrow hematopoietic stem cell transplantation are among the primary therapeutic treatments for AML (2). However, the majority of patients do not have access to treatment options other than chemotherapy, due to the limited medical access and economic conditions in China.

Arsenic trioxide (ATO) was the first successful treatment for acute promyelocytic leukemia (APL), and has improved the clinical outcomes and prolonged the survival of patients with

Correspondence to: Dr Jun Li, Department of Hematology, The First Affiliated Hospital of Bengbu Medical College, 287 Changhuai Road, Bengbu, Anhui 233004, P.R. China

E-mail: jun_li_1978@163.com

Key words: acute myeloid leukemia, arsenic trioxide, ROS proto-oncogene 1 receptor tyrosine kinase, $\mathrm{Wnt} / \beta$-catenin
APL (3-8). Physicians have begun to use ATO to treat types of hematological malignancies other than APL, with AML being the most common (9). However, the suitability of treating hematological malignancies other than APL with ATO, and the molecular mechanism underlying ATO therapy, remains unknown. An improved understanding of the mechanisms associated with ATO may reveal its potential therapeutic value for treating AML.

A number of malignant tumor types exhibit abnormal expression of ROS proto-oncogene 1 receptor tyrosine kinase (ROS1), a gene associated with the Wnt/ $\beta$-catenin signaling pathway (10-14). ROS1 is considered a potential target for cancer treatment and targeted anticancer therapies are under development (15). If ROS1 inhibitors may be used in combination with ATO to treat patients with AML, the therapeutic efficacy may be improved and adverse effects may be decreased. In addition, novel applications of approved drugs may decrease the costs associated with researching and developing novel agents. Thus, in the present study, the function of ROS1 in the ATO-treatment of AML cells has been evaluated.

\section{Materials and methods}

Cell lines. The AML cell lines used in this study include THP-1 (organism, Homo sapien/human; cell type, monocyte; tissue, peripheral blood; disease, acute monocytic leukemia; product format, frozen), HL60 (organism, Homo sapien/human; cell type, promyeloblast; tissue, peripheral blood; disease, acute promyelocytic leukemia; product format, frozen) and Kasumi-6 (organism, Homo sapien/human; cell type: myeloblast; tissue, peripheral blood; disease, acute myeloid leukemia subtype M2; product format, frozen). All cell lines were purchased from Shenyang Yike Biological Technology Co., Ltd. (Shenyang, China).

Transfection. AML cells were transfected with human ROS1-specific or control small interfering (si)RNAs using Lipofectamine ${ }^{\circledR} 2000$ (Invitrogen; Thermo Fisher Scientific, Inc., Waltham, MA, USA), according to the manufacturer's protocol. Functionally-validated siRNA (1 nmol) against ROS1 gene with target sequence of 5'-AAGGTAATTGCTCTAACT TTA-3'. The ROS1-silenced (ROS1-si) and siRNA-transfected control (ROS1-c) cells were harvested $48 \mathrm{~h}$ following transfection, and the efficacy of ROS1 silencing was determined using western blot analysis. 
Western blot analysis. ROS1-si and ROS1-c AML cells were collected $48 \mathrm{~h}$ after transfection. GAPDH and $\beta$-actin were used for control. The protein concentration in the lysates was quantified using an enhanced bicinchoninic acid protein assay kit (Thermo Fisher Scientific, Inc.) with bovine serum albumin (BSA; Invitrogen; Thermo Fisher Scientific, Inc.) as a standard; $30 \mu \mathrm{g}$ protein was added per lane. The protein extracts were subjected to $7.5 \%$ SDS-PAGE at $200 \mathrm{~V}$ for $40 \mathrm{~min}$ and the resolved proteins were electro-transferred for $12 \mathrm{~min}$ at $18 \mathrm{~V}$ to nitrocellulose membranes (Thermo Fisher Scientific, Inc.) using a western blotting semi-dry transfer unit (Hoefer, San Francisco, CA, USA). The membranes were blocked for $1 \mathrm{~h}$ at room temperature with TBST (10X buffer; $200 \mathrm{mM}$ Tris base, $1.5 \mathrm{M} \mathrm{NaCl}$ in MiliQ water; $0.1 \%$ Tween-20 was added and $\mathrm{pH}$ was adjusted to 7.5 for $1 \mathrm{X}$ buffer) containing $5 \%$ BSA The membranes were then incubated with one of the primary antibodies (1:200) [rabbit anti-ROS 1 (cat no. MA5-26180; Invitrogen; Thermo Fisher Scientific, Inc.), rabbit anti-Axin (cat no. 34-5900; Invitrogen; Thermo Fisher Scientific, Inc.), rabbit anti-GSK-3 $\beta$ (cat no. A170132; Invitrogen; Thermo Fisher Scientific, Inc.), rabbit anti-APC (cat no. 17-9956-42; Invitrogen; Thermo Fisher Scientific, Inc.), rabbit anti- $\beta$-catenin (cat no. 71-2700; Invitrogen; Thermo Fisher Scientific, Inc.), rabbit anti-c-Myc (cat no. MA1-980; Invitrogen; Thermo Fisher Scientific, Inc.), rabbit anti-Cyclin-D1 (cat no. PA5-16777; Invitrogen; Thermo Fisher Scientific, Inc.), rabbit anti-PPAR- $\alpha$ (cat no. PA1-820; Invitrogen; Thermo Fisher Scientific, Inc.), rabbit anti-MMP-7 (cat no. PA1-9069; Invitrogen; Thermo Fisher Scientific, Inc.), rabbit anti-GAPDH (cat no. PA1-988; Invitrogen; Thermo Fisher Scientific, Inc.) and rabbit anti- $\beta$-actin (cat no. PA1-183; Invitrogen; Thermo Fisher Scientific, Inc.)] in TBST with 5\% BSA overnight at $4^{\circ} \mathrm{C}$ with gentle shaking. Membranes were washed twice with TBST for 10 min each and additionally incubated with secondary antibody (goat anti-rabbit; cat no. A11008; 1:5,000; Invitrogen; Thermo Fisher Scientific, Inc.) for $1 \mathrm{~h}$ at room temperature. Then the membrane was washed 2 times for 10 min each with TBST to remove any non-bound secondary antibody. The membrane was incubated with Pierce ECL western-blotting Detection Reagent (Bio-Rad Laboratories, Inc., Hercules, CA, USA) at room temperature for $5 \mathrm{~min}$. Excess detection reagent was removed and the membrane was exposed to X-ray film placed on top of the membrane for $6 \mathrm{~min}$ in an X-ray film cassette (Amersham; GE Healthcare, Chicago, IL, USA). Membranes were also assessed for equal loading. The degree of target protein downregulation in ROS1-si cells relative to the control cells was determined by gray level analysis, which was calculated by area and pixel values, using Image $\mathbf{J}$ software (National Institutes of Health, Bethesda, MD, USA).

Measurement of cell growth. THP-1, HL60 and Kasumi- 6 cells (3x $10^{3}$ cells/well) were transferred to 96 -well plates and treated with $2.5 \mu \mathrm{M}$ ATO (Harbin Pharmaceutical Group Co., Ltd., Harbin, China) for $72 \mathrm{~h}$ at $37^{\circ} \mathrm{C}$ in an atmosphere containing $5 \% \mathrm{CO}_{2}$. The effect of ROS1 knockdown on cell proliferation in THP-1, HL60 and Kasumi-6 cells was determined using a Cell Counting Kit-8 (Dojindo Molecular Technologies, Inc., Kumamoto, Japan), as described previously $(16,17)$.

For cell migration assays, transfected THP-1, HL60 and Kasumi- 6 cells $\left(5 \times 10^{5}\right.$ cells/well) were seeded in $250 \mu \mathrm{l}$ RPMI-1640 medium (Gibco; Thermo Fisher Scientific, Inc.),

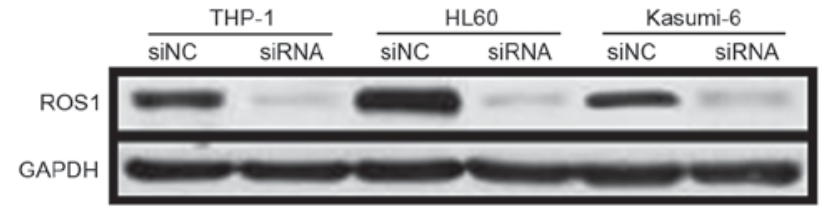

Figure 1. Efficacy of ROS1 knockdown in THP-1, HL60 and Kasumi-6 cell lines by siRNA. ROS1 was successfully silenced in all three cell lines. GADPH was used as the loading control. siRNA, short interfering RNA; NC, negative control.

without fetal bovine serum (FBS), into the upper chamber of a Transwell plate (with $8 \mu \mathrm{m}$ pores; Corning Incorporated, Corning, NY, USA). RPMI-1640 (Invitrogen; Thermo Fisher Scientific, Inc.) with 10\% FBS (Invitrogen; Thermo Fisher Scientific, Inc.) was added into the lower chamber. These cells were incubated at $37^{\circ} \mathrm{C}$ in an atmosphere containing $5 \% \mathrm{CO}_{2}$ for between 48 and $72 \mathrm{~h}$. Cells were stained at room temperature for $\sim 10$ min and observed using light microscopy at magnification, $x 100$. Each experiment was repeated in triplicate.

Statistical analysis. All data were analyzed using SPSS 19.0 (IBM Corp., Armonk, NY, USA). Data from the three different samples are presented as the mean \pm standard deviation, and the differences among them were compared by analysis of variance, followed by. a Student Newman Keuls post-hoc test, and $\mathrm{P}<0.05$ was considered to indicate a statistically significant difference.

\section{Results}

ROS1 is silenced successfully in THP-1, HL60 and Kasumi-6 cells. In order to determine the efficacy of gene silencing, the expression levels of ROS1 in THP-1, HL60 and Kasumi-6 cell lines were determined using western blot analysis. ROS1 expression was markedly decreased in cells following transfection with human ROS1-specific siRNA compared with control cells (Fig. 1).

ATO inhibits the migratory and proliferative abilities of THP-1, HL60 and Kasumi-6 cells. The effects of ATO on the migratory and proliferative capabilities of THP-1, HL60 and Kasumi- 6 cells was determined in vitro. The results demonstrated that ATO treatment significantly inhibited cell migration and proliferation in these three cell lines $(\mathrm{P}=0.003$, 0.007, and 0.014, respectively) (Fig. 2).

ROS1 knockdown increases the sensitivity of AML cells to ATO treatment. Following ROS1 knockdown by siRNA, THP-1, HL60 and Kasumi-6 cells were treated with $2.5 \mu \mathrm{M}$ ATO. The results revealed that cell migration and proliferation was significantly inhibited by the combination of ROS1 knockdown and ATO treatment, compared with ATO treatment alone (all $\mathrm{P}<0.001)$ (Fig. 3). This result suggests that ROS1 knockdown sensitized AML cells to the effects of ATO, and that ROS1 is involved in the migration and proliferation of leukemia cells.

ROS1 silencing inhibits Wnt/ $\beta$-catenin signaling in AML cells. Proliferation and migration of AML cells are regulated by a number of signaling pathways, including the Wnt/ $\beta$-catenin 

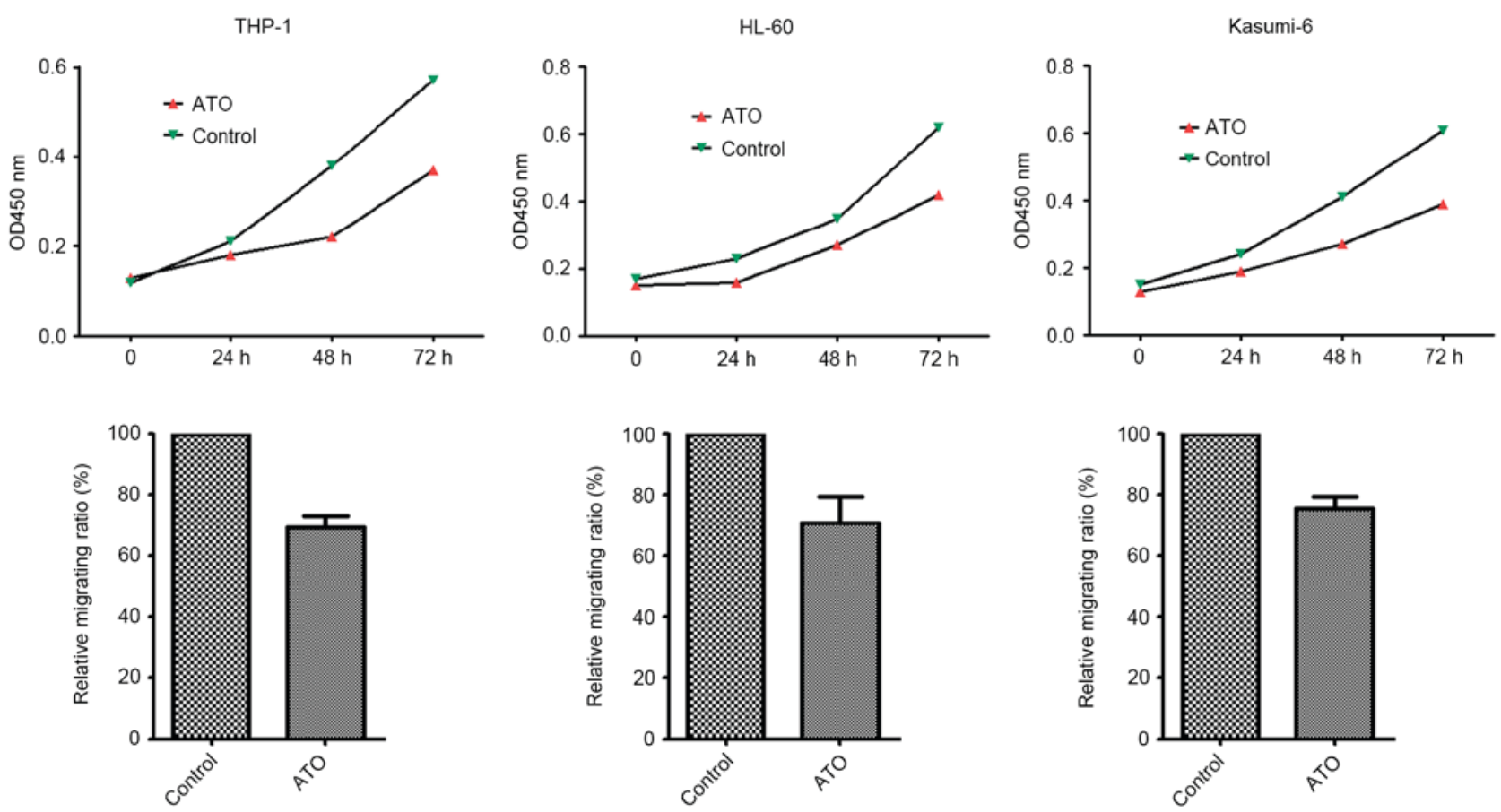

Figure 2. ATO treatment inhibited the proliferation and migration of THP-1, HL60 and Kasumi- 6 cells. The bars represent mean \pm standard deviation. ATO, arsenic trioxide; OD, optical density.

THP-1
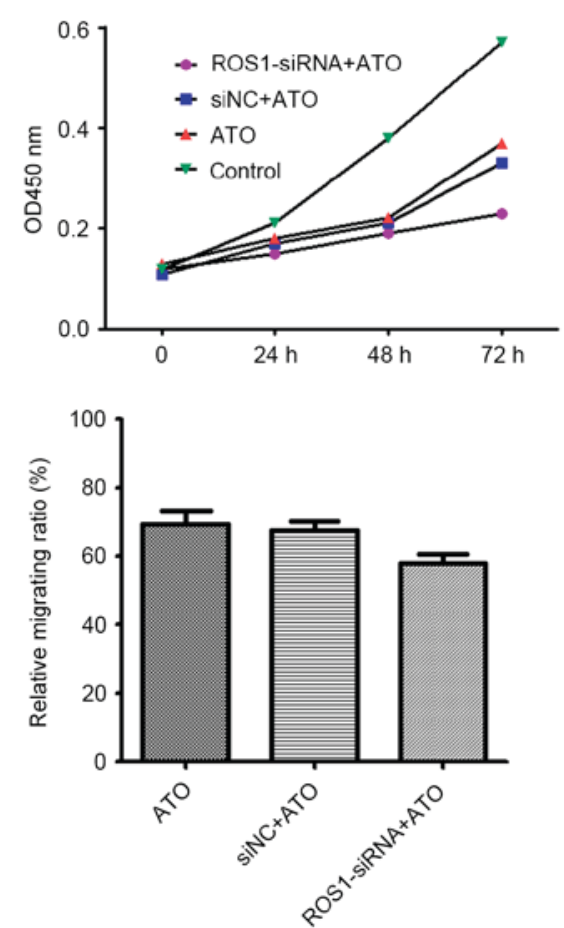

HL-60
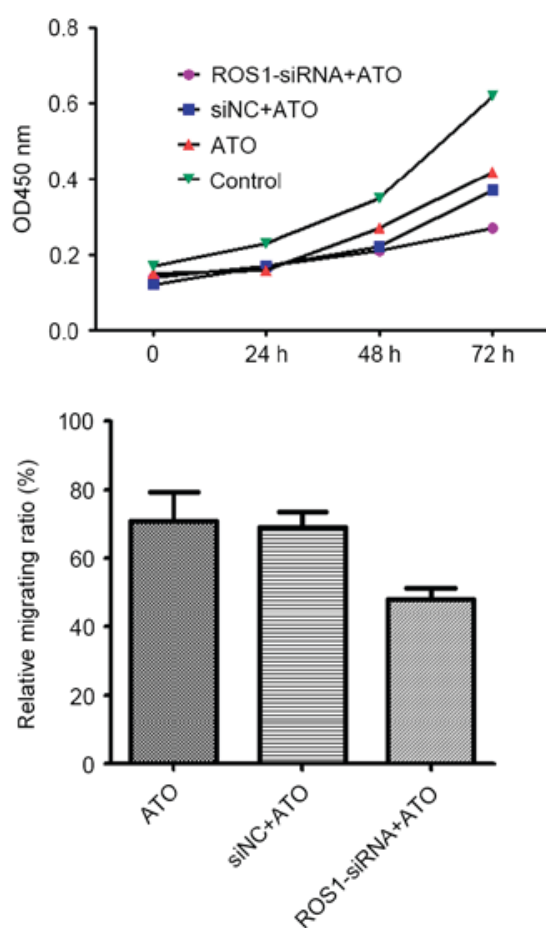

Kasumi-6
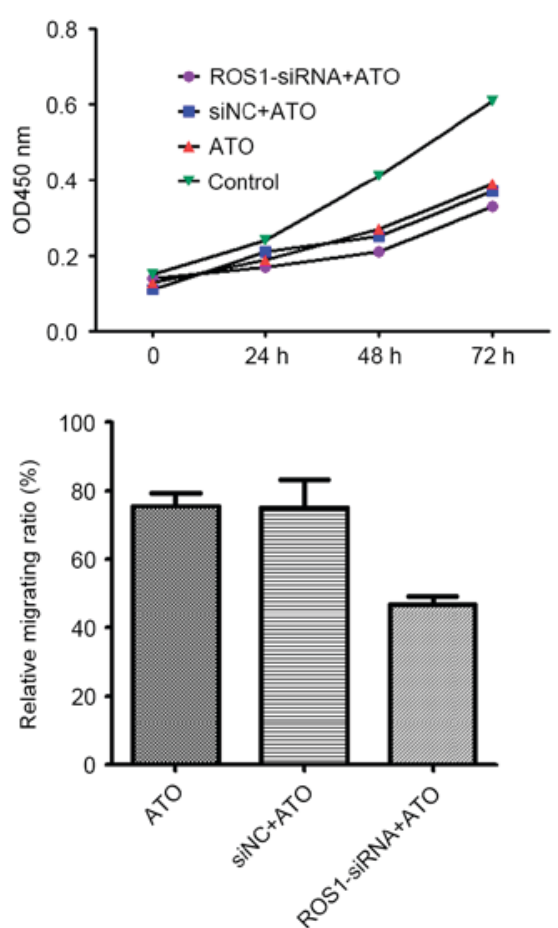

Figure 3. ROS1 knockdown sensitized THP-1, HL60 and Kasumi-6 cells to ATO treatment. The bars represent mean \pm standard deviation. ROS1, ROS proto-oncogene 1 receptor tyrosine kinase; ATO, arsenic trioxide; OD, optical density; siRNA, short interfering RNA; NC, negative control.

pathway. Therefore, in the present study, the effect of ROS1 silencing on $\mathrm{Wnt} / \beta$-catenin activation in AML cells was investigated using western blot analysis (Fig. 4). The relative levels of Axin, glycogen synthase kinase-3 $\beta$, Adenomatous polyposis coli and peroxisome proliferator-activator receptor $\alpha$ were markedly increased in ROS1-si cells, compared with in ROS1-c cells. The relative levels of $\beta$-catenin, c-Myc, cyclin D1, and matrix metalloproteinase-7 were markedly decreased in ROS1-si cells, compared with in ROS1-c cells. These data indicate that ROS1 silencing inhibits Wnt/ $\beta$-catenin activation, which is crucial for the proliferation and migration of AML cells. 


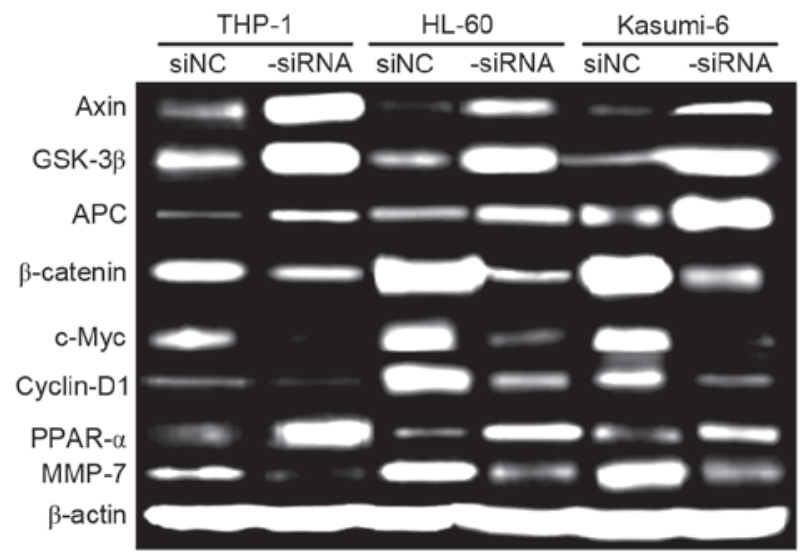

Figure 4. Relative levels of target proteins in ROS1-si and ROS1-c AML cells, cultured for $72 \mathrm{~h}$, as determined using western blot analysis. $\beta$-catenin was the loading control. ROS1, ROS proto-oncogene 1 receptor tyrosine kinase; -si, ROS1-silenced; -c, siRNA-transfected control; AML, acute myeloid

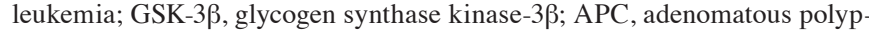
osis coli; PPAR- $\alpha$, peroxisome proliferator-activator receptor $\alpha$; MMP-7, matrix metalloproteinase-7.

\section{Discussion}

In the present study, it was identified that ATO treatment inhibited the migration and proliferation of THP-1, HL60 and Kasumi-6 leukemia cell lines, which was mediated by ROS1. Knockdown of ROS1 expression sensitized the three leukemia cell lines to ATO treatment and inhibited the $\mathrm{Wnt} / \beta$-catenin signaling pathway. Knockdown of ROS1 expression alone decreased the migration and proliferation of the three cell lines, but not significantly (data not presented).

ATO promotes apoptosis and other biological responses in tumor cells, which has prompted its use in the treatment of APL and other types of hematological malignancies, including multiple myeloma (16-20), and cancer of the breast, brain, liver, stomach, prostate, kidney and bladder $(21,22)$. However, toxicity to the liver, heart and level $3 / 4$ peripheral nerves rises with increasing ATO dosage $(19,23)$, which effects therapeutic efficacy and patient compliance. Therefore, increasing the therapeutic window of ATO is important. In this respect, ROS1 downregulation represents a potential therapeutic strategy that requires additional investigation.

A number of signal transduction pathways regulate the biology of leukemia. Among them, the Wnt signaling pathway is one of the best characterized. Wnt signaling serves functions in the development of leukemia and is important for the survival and self-renewal of leukemia cells (24-26). Notably, the Wnt signaling pathway is associated with the maintenance of leukemia stem cells, which is directly associated with disease progression $(27,28)$. $\beta$-catenin is maintained in an activated state in these leukemia cells and is expressed in a number of types of tumor (29-32). Previous studies have suggested that ROS1 may be involved in the regulation of Wnt signaling (33). The results of the present study provided insights into the regulation of Wnt signaling, although additional studies are required. For example, in the present study, it was observed that alterations in ROS1 expression resulted in alterations to the expression of proteins associated with Wnt signaling. However, the association between ROS1 and Wnt signaling remains unknown and, in particular, the functions ROS1 serves in the regulatory network of Wnt signaling. In addition, the regulation of Wnt signaling by ROS1 and sensitization of AML cells to ATO treatment by ROS1 downregulation requires validation in animal studies.

The present study demonstrated that knockdown of ROS1 expression enhanced the migration and proliferation of leukemia cell lines, and suppressed $\mathrm{Wnt} / \beta$-catenin activation. The results of the present study suggested that ROS1 may be a therapeutic target and a sensitizer for ATO treatment in patients with AML. Therefore, the present study provided novel insight into the function of ROS1 in regulating AML progression and ATO treatment.

\section{Acknowledgements}

Not applicable.

\section{Funding}

Funding information is not applicable.

\section{Availability of data and materials}

The datasets analyzed during the current study are available from the corresponding author on reasonable request.

\section{Authors' contributions}

JL designed the study, conducted the statistical analysis and drafted of the article, and read and approved the final manuscript.

\section{Ethics approval and consent to participate}

Not applicable.

\section{Consent for publication}

Not applicable.

\section{Competing interests}

The author declares that he has no competing interests.

\section{References}

1. Estey E and Döhner H: Acute myeloid leukaemia. Lancet 368: 1894-1907, 2006.

2. Estey EH: Acute myeloid leukemia: 2013 update on risk-stratification and management. Am J Hematol 88: 318-327, 2013.

3. Coombs CC, Tavakkoli M and Tallman MS: Acute promyelocytic leukemia: Where did we start, where are we now, and the future. Blood Cancer J 5: e304, 2015.

4. Cicconi L and Lo-Coco F: Current management of newly diagnosed acute promyelocytic leukemia. Ann Oncol 27: 1474-1481, 2016.

5. Lo-Coco F, Cicconi L and Breccia M: Current standard treatment of adult acute promyelocytic leukaemia. Br J Haematol 172: 841-854, 2016.

6. Sanz MA and Lo-Coco F: Modern approaches to treating acute promyelocytic leukemia. J Clin Oncol 29: 495-503, 2011.

7. Zhu J, Chen Z, Lallemand-Breitenbach V and de Thé H: How acute promyelocytic leukaemia revived arsenic. Nat Rev Cancer 2: 705-713, 2002. 
8. de Thé $\mathrm{H}$ and Chen Z: Acute promyelocytic leukaemia: Novel insights into the mechanisms of cure. Nat Rev Cancer 10: 775-783, 2010.

9. Takahashi S: Combination therapy with arsenic trioxide for hematological malignancies. Anticancer Agents Med Chem 10: 504-510, 2010

10. Shaw AT, Hsu PP, Awad MM and Engelman JA: Tyrosine kinase gene rearrangements in epithelial malignancies. Nat Rev Cancer 13: 772-787, 2013

11. El-Deeb IM, Yoo KH and Lee SH: ROS receptor tyrosine kinase: A new potential target for anticancer drugs. Med Res Rev 31 794-818, 2011

12. Ye M, Zhang X, Li N, Zhang Y, Jing P, Chang N, Wu J, Ren X and Zhang J: ALK and ROS1 as targeted therapy paradigms and clinical implications to overcome crizotinib resistance. Oncotarget 7: 12289-12304, 2016.

13. Arnaoutakis K: Crizotinib in ROS1-rearranged non-small-cell lung cancer. N Engl J Med 372: 683, 2015.

14. Gold KA: ROS1-targeting the one percent in lung cancer. N Engl J Med 371: 2030-2031, 2014

15. Lambros L, Guibourg B and Uguen A: ROS1-rearranged non-small cell lung cancers with concomitant oncogenic driver alterations: About some rare therapeutic dilemmas. Clin Lung Cancer 19: e73-e74, 2018.

16. Murgo AJ: Clinical trials of arsenic trioxide in hematologic and solid tumors: Overview of the national cancer institute cooperative research and development studies. Oncologist 6 (Suppl 2): S22-S28, 2001.

17. Tallman MS: What is the role of arsenic in newly diagnosed APL? Best Pract Res Clin Haematol 21: 659-666, 2008.

18. Berenson JR and Yeh HS: Arsenic compounds in the treatment of multiple myeloma: A new role for a historical remedy. Clin Lymphoma Myeloma 7: 192-198, 2006.

19. Evens AM, Tallman MS and Gartenhaus RB: The potential of arsenic trioxide in the treatment of malignant disease: Past, present, and future. Leuk Res 28: 891-900, 2004.

20. Baj G, Arnulfo A, Deaglio S, Mallone R, Vigone A, De Cesaris MG, Surico N, Malavasi F and Ferrero E: Arsenic trioxide and breast cancer: Analysis of the apoptotic, differentiative and immunomodulatory effects. Breast Cancer Res Treat 73 61-73, 2002.

21. Chen Z, Chen GQ, Shen ZX, Sun GL, Tong JH, Wang ZY and Chen SJ: Expanding the use of arsenic trioxide: Leukemias and beyond. Semin Hematol 39 (2 Suppl 1): S22-S26, 2002.

22. Dilda PJ and Hogg PJ: Arsenical-based cancer drugs. Cancer Treat Rev 33: 542-564, 2007.
23. Verstovsek S, Giles F, Quintás-Cardama A, Perez N, Ravandi-Kashani F, Beran M, Freireich E and Kantarjian H: Arsenic derivatives in hematologic malignancies: A role beyond acute promyelocytic leukemia? Hematol Oncol 24: 181-188, 2006.

24. Eaves CJ and Humphries RK: Acute myeloid leukemia and the Wnt pathway. N Engl J Med 362: 2326-2327, 2010.

25. Caye A, Strullu M, Guidez F, Cassinat B, Gazal S, Fenneteau O, Lainey E, Nouri K, Nakhaei-Rad S, Dvorsky R, et al: Juvenile myelomonocytic leukemia displays mutations in components of the RAS pathway and the PRC2 network. Nat Genet 47: 1334-1340, 2015.

26. Zhang H, Peng C, Hu Y, Li H, Sheng Z, Chen Y, Sullivan C, Cerny J, Hutchinson L, Higgins A, et al: The Blk pathway functions as a tumor suppressor in chronic myeloid leukemia stem cells. Nat Genet 44: 861-871, 2012.

27. Kühnl A, Valk PJ, Sanders MA, Ivey A, Hills RK, Mills KI, Gale RE, Kaiser MF, Dillon R,Joannides M, et al: Downregulation of the Wnt inhibitor CXXC5 predicts a better prognosis in acute myeloid leukemia. Blood 125: 2985-2994, 2015.

28. Wang Y, Krivtsov AV, Sinha AU, North TE, Goessling W, Feng Z, Zon LI and Armstrong SA: The Wnt/beta-catenin pathway is required for the development of leukemia stem cells in AML. Science 327: 1650-1653, 2010.

29. Heidel FH, Bullinger L, Feng Z, Wang Z, Neff TA, Stein L, Kalaitzidis D, Lane SW and Armstrong SA: Genetic and pharmacologic inhibition of $\beta$-catenin targets imatinib-resistant leukemia stem cells in CML. Cell Stem Cell 10: 412-424, 2012.

30. Kleppe $M$ and Levine RL: Targeting $\beta$-catenin in CML: Leukemia stem cells beware! Cell Stem Cell 10: 351-353, 2012.

31. Hoffmeyer K, Raggioli A, Rudloff S, Anton R, Hierholzer A, Del Valle I, Hein K, Vogt R and Kemler R: Wnt/ $\beta$-catenin signaling regulates telomerase in stem cells and cancer cells. Science 336 : 1549-1554, 2012.

32. Morikawa T, Kuchiba A, Yamauchi M, Meyerhardt JA, Shima K, Nosho K, Chan AT, Giovannucci E, Fuchs CS and Ogino S: Association of CTNNB1 (beta-catenin) alterations, body mass index, and physical activity with survival in patients with colorectal cancer. JAMA 305: 1685-1694, 2011.

33. Wang K, Li N, Yeung CH, Cooper TG, Liu XX, Liu J, Wang WT, $\mathrm{Li}$ Y, Shi H and Liu FJ: Comparison of gene expression of the oncogenic Wnt/ $\beta$-catenin signaling pathway components in the mouse and human epididymis. Asian J Androl 17: 1006-1011, 2015. 